\title{
Innovative microelectronic technologies for high-energy physics experiments
}

\author{
V.M.Borshchov, O.M.Listratenko, M.A.Protsenko, \\ I.T.Tymchuk, O.O.Fomin
}

\author{
"LED Technologies of Ukraine" Ltd, 3 Novgorodskaya Str., 61145 \\ Kharkiv, Ukraine
}

Received September, 29, 2016

\begin{abstract}
In the paper there are proposed new approaches to for creating the innovative designtechnological solutions and manufacture technologies of advanced thin pixel array detector modules based on high resolution CMOS monolithic active pixel sensors as well as flexible adhesiveless aluminium-polyimide flexible boards and cables for high-energy physics experiments.
\end{abstract}

Keywords: thin pixel sensor, detector module, flexible board.

Предложены новые подходы к созданию инновационных конструктивно-технологических решений и технологий изготовления усовершенствованных тонких пиксельных матричных детекторных модулей на основе КМОП монолитных активных пиксельных сенсоров высокого разрешения, а также гибких безадгезивных алюминий-полиимидных коммутационных плат и шлейфов для экспериментов в физике высоких энергий.

Інноваційні мікроелектронні технології для експериментів у фізиці високих енергій. В.М.Борщов, О.М.Лістратенко, М.А.Проценко, І.Т.Тимчук, О.О.Фолін .

Запропоновано нові підходи до створення інноваційних конструктивно-технологічних рішень і технологій виготовлення удосконалених тонких піксельних матричних детекторних модулів на основі КМОП монолітних активних піксельних сенсорів високої роздільної здатності, а також гнучких безадгезивних алюміній-поліімідних комутаційних плат і шлейфів для експериментів у фізиці високих енергій.

\section{Introduction}

In recent decades microelectronics is extensively implementing in nuclear electronics $[1,2]$ what ensures compliance with the increasing requirements for the nuclear electronics. In experimental studies in high and ultrahigh energy physics there are widely using multi-channel detectors of charged particles and associated readout electronics based on modern semiconductor devices structured in standard modules. Due to the huge amount of readout information it is necessary to solve problems associated with the data transfer between different devices and electronic units under tight time constraints. Moreover at joint functioning the large number of the detector modules it is necessary to solve the problem of noise immunity of their constituent devices and reducing the interference generated by them. These problems are solved sequentially at system engineering, circuitry and design-technological levels [3, 4].

Semiconductor sensors in the detector systems in high-energy physics for more than fifty years are used. The basic material for the sensors is silicon due to its properties such as a small band gap, high charge carrier mobility, rather high lifetime of electron-hole pairs, and ability to operate at the room temperature. For development of the silicon sensors and detector modules based on them in the high-energy physics 
two things have become extremely important. First of all it is planar technology which allows to create rather complex structure on silicon surface; secondly it is creation of microminiature integrated circuits (IC) which became possible to place in the immediate vicinity to the sensor.

According to functional principle the silicon sensors can be divided into three main types: microstrip, drift and pixel. In microstrip, as in the drift sensors also, sensitive cell is a "strip" - line width up to hundreds of micrometers and length up to tens of centimeters (in the case if several strips of the sensors are connected in one line). In drift and pixel sensors the sensitive cell has comparable value of length and width which might be from a few millimeters up to tens of micrometers. The pixel systems are used under high events level thus allow to reduce frequency of events in a single cell. Opposite side of this advantage is that it is necessary to read a larger number of information channels. The pixel sensor determines two coordinates at the same time. In the microstrip detectors for such goal there are used double sided sensors or two single sided sensors which are mounted "back-toback" with overlapping of their strips.

The high charge carrier mobility in silicon ensures fast collecting of formed charge. For typical microstrip detectors this time is about $10 \mathrm{~ns}$. Small coefficient of diffusion allows charge transporting over long distances without significant loss of accuracy of coordinate measurements what allows successful implementation of the development and creation of silicon drift sensors [2]. Furthermore use of the standard detector modules can solve the problem of minimizing the material budget in detection volume, simplification and increasing the productivity of assembly processes while maintaining the high packaging density and high reliability at creation of the new generation of hybrids and connecting cables. However despite of the significant advantages in the development of different types of the hybrid microcircuits and detector modules on their base the possibilities of creation of the new more advanced designs and manufacture technologies with using the multi-layered flexible-rigid boards and flexible connecting cables in the detector modules are still not well implemented.

Such conclusion can be fully attributed to the current pixel detector modules. Due to fact that silicon pixel sensors determine two coordinates at once with the high reso- lution due to the small size of pixels (tens micrometers) now they are increasingly used in the detector systems in the high-energy physics experiments. In addition the array location of contacts provides the highest packing density and maximal number of contacts on the sensor. Moreover minimal transient capacitance of the contacts is better compared to other types of sensors and it allows to operate at the higher frequencies of outside information line. That is one of the most important aspects of research with increasing the information content and therefore significant increasing of information flows. The array system of leads makes possible placement of a large number of interconnections on a limited area of the sensors [5-7].

Thus the goal of this work is development and verification of effective approaches to creation of the modern innovative design and technological solutions and manufacture technologies of improved pixel array detector modules based on flexible less adhesive aluminum-polyimide boards and cables with using ultrasonic welding automated processes and COF (Chip-on-Flex) assembly technology. Innovative solutions of the pixel detector modules based on the new generation of silicon pixel sensors might be used for creation of the new and upgrade of existing detector systems for the high-energy physics experiments.

\section{Experimental}

\subsection{Pixel array sensors}

Pixel array silicon sensors were first used in the detector system of ATLAS experiment which is currently carrying out at Large Hadron Collider (LHC) at the European Organization for Nuclear Research, known as CERN (Geneva, Switzerland). Such sensors were used in ALICE, LHCb and CMS experiments also carried out at LHC [8].

In design of the pixel sensors there were applied the array arrangement of ball leads BGA-type (BGA-Ball Grid Array). Such approach provided some obvious advantages:

- minimal area of mounting surface of commutation board;

- best conditions to ensure of functional performance of the electronic modules due to lower parasitic effects during high-speed operating;

- simplification of surface mount technology on commutation element due to use of processes for group reflow heating;

- high yield. 
For connection of volumetric ball leads the common and well-known soldering method is used. However in this case the mounting of sensors with such leads associated with substantial additional investments in equipment for ensuring the leads positioning on the board and solder joints quality tests which are not available for visualization. At the same time there is always danger of decreasing of connections quality because of complicated controlled soldering processes. Limited length of the leads does not ensure damping for compensation of mismatches of thermal expansions of the materials in interconnects and it does not provides necessary conditions for the specific resistance to mechanical stress which can deform the substrate.

Thereby list of materials for use in such constructions is very limited and they are expensive enough. Trend towards further reducing the leads pitch (less than $1 \mathrm{~mm}$ ) exacerbates this problem [6].

Alternative technology for creating the detector modules is COF technology. Usage of such technology with help of ultrasonic welding processes of flexible single- and multi-layered board allows ensure the damping for compensating mismatch in thermal expansion of the materials in interconnections between flat pads of rigid sensors and flexible boards in the detector modules. In this case BGA or COB (Chip-on-Board) assembly technologies are no needed. Moreover manufacture process for silicon pixel sensors is significantly simplified because of there is no need to form the rigid ball leads on the sensors' contact pads and tinning pads on the commutation elements is not required also [8].

At direct mounting of the silicon pixel array sensors on board it is great interest to use flexible foiled dielectrics as material for commutation elements. Flexible printed circuit boards on their base are various systems of flexible commutation elements which might include single-, double- and multi-layered interconnect structures. Their designs can be flexible or combined from the rigid and flexible parts.

Using the flexible boards and flexible cables based on copper-polyimide foiled dielectrics in constructions of detector modules and hybrids allows in some way to solve the problem of minimizing volume of the detector systems in the high-energy physics experiments [9] and also implements the possibility of three-dimensional arrangement of the detector modules and ensures their as- sembly without the "dead areas" with high energy and spatial resolutions. However application of adhesive and adhesive less polyimide films with copper conductive layer does not allow to fully provide advantages of COF-technology in the detector modules assembly. There were some unsolved problems inherent in the traditional COF-technology based on copper-polyimide foiled dielectrics. To ensure the reliable connection without corrosion with aluminum pads of chips and sensors on copper conductors of the flexible circuit boards and cables it is necessary to coat additional nickel and gold layers. This is complicate and makes more expensive the process of forming the flexible commutation elements. Furthermore, the forming by ultrasonic welding interconnects of the flexible cables with sensors and chips using aluminum wire restricts the possibility of reduction of the dimensions and volume of the detector modules and it requires higher accuracy and care during assembly to prevent deformation of the aluminum wire interconnects and for excluding shorts between them [10].

From this point of view the most optimal option for further improvement of the COFassembly technology in nuclear electronics devices is use of aluminum-polyimide less adhesive lacquer foiled dielectrics, i.e., aluminum COF-technology. The less adhesive lacquer foiled aluminum-polyimide dielectrics have all advantages same as copperpolyimide materials [11]. However a number of additional advantages over copper-polyimide foiled dielectrics might significantly enhance the ability of the COF-technology at present stage.

The main advantages of aluminum-polyimide lacquer foiled dielectrics are following:

- aluminum has high corrosion resistance;

- aluminum has radiation length exceeding nearly 6 times the radiation length of copper $\left(X_{0 \mathrm{Al}} \approx 8.9 \mathrm{~cm}, X_{0 \mathrm{Cu}} \approx 1.43 \mathrm{~cm}\right)$;

- despite of aluminum has a lower mechanical strength compared to copper $\left(\sigma_{A l}=\right.$ (10-40) $\left.\mathrm{MPa}, \sigma_{\mathrm{Al}}=(16-45) \mathrm{MPa}\right)$, lower thermal conductivity $\left(\lambda_{\mathrm{TAl}}=218 \mathrm{~W} /(\mathrm{m} \cdot \mathrm{K})\right.$, $\left.\lambda_{\mathrm{TCu}}=385 \mathrm{~W} /(\mathrm{m} \cdot \mathrm{K})\right)$, electrical resistivity is about 1.6 times higher as for copper $\left(\rho_{\mathrm{Al}}=\right.$ $\left.0,028 \mu \mathrm{Ohm} \cdot \mathrm{m} ; \quad \rho_{\mathrm{Cu}}=0.017 \mu \mathrm{Ohm} \cdot \mathrm{m}\right)$, it should be to be noted facts that aluminum is almost 3.5 times lighter than copper $\left(\gamma_{\mathrm{Al}}=\right.$ $2.7 \mathrm{~g} / \mathrm{cm}^{3}, \gamma_{\mathrm{Cu}}=8.92 \mathrm{~g} / \mathrm{cm}^{3}$ ) and more than 2 times cheaper; 
- due to low density of aluminum it is ensuring the higher electrical conductivity per unit of mass (i.e., at the same value of resistance and the same length the aluminum conductors are almost two times lighter than the copper ones in spite of the larger cross-section).

Thus the commutation elements based on aluminum-polyimide lacquer foiled dielectrics allow more minimize the material budget in volume of detecting and decrease dimensions of the detector modules what is especially promising for detector systems with the high density of information channels.

Aluminium COF assembly technology is easily adaptable to existing industrial automated equipment for ultrasonic welding of aluminum ribbon leads. This ensures the high quality and reliability of welded joints due to fact that homogeneous materials are welding (the aluminum contact pads of electronic components and aluminum commutation elements). Furthermore the commutation elements based on aluminum-polyimide less adhesive dielectrics can significantly improve capacity characteristics of the electronic devices. Due to additional positive property of aluminum, namely low value of yield strength $\left(\sigma_{0.2}=2 \mathrm{MPa}\right)$ it is possible during ultrasonic welding process to realize the direct connections of flat aluminum traces with pads of sensors through "deep windows" (up to $100 \mu \mathrm{m}$ ) in polyimide. This ensures the reducing output capacitance of the sensor by $5 \div 7$ times what significantly improves sensitivity and resolution of the detector systems [11].

The innovative aluminum COF assembly technology of pixel array detector modules based on new generation of silicon pixel sensors can be successfully applied for upgrade of existing ALICE international experiment at LHC at CERN [13]. The main objective of the new ALICE experiment is to study the properties of matter, in particular, quark-gluon plasma. At the same time the main sensitive area of the detector system in ALICE experiment is Inner Tracking System (ITS) consisting of detector modules arranged around of interaction point. Improvement of upgraded ITS compared to existing one is foreseen by implementation of the following main approaches:

1. Improving parameters of the system by:

- placing detector modules closer to the interaction point (inner layer) to on $23 \mathrm{~mm}$ instead of $39 \mathrm{~mm}$;
- reducing $X / X_{0}$ radiation length ratio for inner layers from $1.14 \%$ down to $0.3 \%$;

- reducing pixel size from $(50 \times 425) \mu \mathrm{m}$ down to $(30 \times 30) \mu \mathrm{m}$;

2. Improving the particle tracking due to:

- increasing the number of detecting layers from 6 layers up to 7 layers;

- replacing drift and microstrip silicon sensors by pixel sensors.

3 . Increasing the readout speed at interaction of the particles from $1 \mathrm{kHz}$ up to more than $100 \mathrm{kHz}$.

From the above mentioned ways of improving the most important and defining technical results are decreasing almost in 4 times the radiation length ratio $X / X_{0}$ and decreasing more than 20 times the pixels area (and thus increasing the number of pixels per unit of area at the sensor).

Thus one of basic conditions which first of all allows perform the above mentioned improvements of the detector system in ALICE experiment is using the supermodern integrated silicon pixel sensors as well as using the advantages of aluminum COF-assembly technology.

\subsection{Integrated pixel array sensor}

Sensors of elementary particles associated with readout electronics which are using for events detection and tracking systems in experiments in the field of elementary particle physics have very strict requirements in terms of integration, material thickness, reading speed, energy consumption and radiation resistance. Development of the sensors based on silicon semiconductor technology and electronic reading based on CMOS (Complementary Metal-OxideSemiconductor) technology, namely Applications Specific Integrated Circuit (ASIC) have has revolutionized the creation of such detection systems in 1980s. Such technology can be used for matching the most of the abovementioned requirements. Taking this into account the silicon microstrip and pixel sensors are main parts of the majority of tracking detector systems presently used in the particle physics experiments. However there are opportunities for further improvements of this technology [12].

Perhaps the most significant in the detection system is organization of interface between the sensor and readout electronics, i.e. they typically are separated the components that are interconnected. For example, all silicon pixel detector modules used in 
the inner layers of the detector systems ATLAS, CMS, LHCb and ALICE experiments at LHC consist of silicon pixel sensors mounted via balls on CMOS chips of the readout electronics [8]. This technology can be improved by thinning both sensor and readout chip ASIC as well as by reducing pitch of the commutation balls. However within this approach there are technical and technological limitations, in particular pitch of the commutation balls, which may not be as small as it is necessary for the modern detectors. To go beyond this limitation and detection system to create, for example, the higher degree of integration and the minimum thickness of material, development of the new approaches and technology are required. The best way to achieve this goal is integration of the sensor and readout electronics to create single monolithic silicon detecting device. Such approach was adopted and successfully implemented in creation of monolithic CMOS Monolithic Active Pixels Sensors (CMOS MAPS). Over past 15 years in the world the large-scale research and developments for creating the MAPS devices were held. It is allowed significantly to raise the level of technology of such monolithic devices and enable their use in the detector systems for experiments in the elementary particle physics. Examples of practical implementation and achievements in creation of the above-mentioned semiconductor devices are following types of MAPS: MIMOSA, MISTRAL, ALPIDE and MuPix chips.

So the ALPIDE type MAPS chips manufactured by Tower Jazz Company (USA) based on radiation resistive $0.18 \mu \mathrm{m}$ CMOS technology were chosen as the main sensitive elements for all inner pixel layers of Inner Tracking System in the new ALICE experiment [12]. This semiconductor device is silicon chip $(15 \times 30) \mathrm{mm}^{2}$ size. There it is formed the high-resistance silicon epitaxial layer (active sensor volume), array of diodes (pixels) for charge collecting with pitch about $30 \mu \mathrm{m}$, and electronics, which performs amplification and digitization of selection of the useful signals from noise background. In this case it is read the information on passing particles through the pixels (Fig. 1).

\subsection{Key features of CMOS MAPS tech- nology}

Due to the modern design level of CMOS chip is $0.18 \mu \mathrm{m}$ and the thickness of gate oxide in MOS devices less than $4 \mathrm{~nm}$ it is

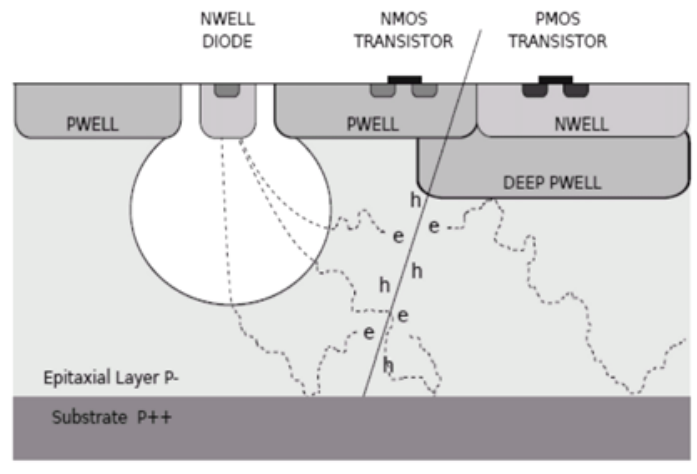

Fig. 1. Schematic cross-section of MAPS sensor.

expected that new CMOS structures will increase the radiation resistance of the chips. Accordingly it will be increased reliability and their resistance to total absorbed dose compared to other CMOS technologies, for example, for $0.35 \mu \mathrm{m}$ design level, which is still basic technology for production of the CMOS sensors for the field of elementary particle physics research.

Small size of transistors and large number of metallization layers (up to six) allow to realize the high level of integration and low power consumption of the digital circuits. That is important because the most digital circuits (e.g., memory) should be located at the periphery of the pixel array area and should be minimized to reduce the size of the sensor as it is possible.

Integrated circuits are manufactured on wafers with epitaxial layer up to $40 \mu \mathrm{m}$ thick and with resistivity in range from $1 \mathrm{kOhm} \cdot \mathrm{cm}$ up to $6 \mathrm{kOhm} \cdot \mathrm{cm}$. At $\mathrm{such}$ value of resistance the thin epitaxial layers can be fully depleted at applying the low reverse bias voltage. This provides increasing the signal-to-noise ration and the high resistance areas which are not exposed to ionizing radiation.

Access to the latest technologies of forming topology of IC providing a predetermined design rules and limits allow producing of the high-quality pixel sensors on silicon wafers with 200-250 $\mathrm{mm}$ diameter. As a result the difference in sensitivity between neighboring chips on the wafer is minimal what simplify selection of sensors in the detector system with the same characteristics. Presence of deep $p$-well with improved properties allows creating the pixel structure with significantly enhanced functionality. This is a unique feature of this technology and it is a key solution to create low-power con- 
sumption architecture of the readout system. The deep $p$-well in area of structures of field-effect transistors allows reducing the capacitance of sensitive electrodes and therefore reducing the electricity consumption in the readout electronics. $N$-region located in $p$-channel of MOS (Metall Oxide Semiconductor) transistor is formed over the deep $p$-well. Electrons formed when particle is passing through the particle sensor are reflecting from the $p$ - $n$-junction between the epitaxial region and the deep $p$ well and collecting by sensitive area. Value of collected charge then is converting (reading) to estimation of effectiveness of detecting and evaluation of the signal-tonoise ratio by using CMOS cells introduced into the pixel.

To minimize the material budget of Inner Tracking System integrated pixel array sensor must be made as thin as possible. Its minimum thickness is determined by thickness of the epitaxial layer (nominal thickness $-18 \mathrm{~mm}$ ) plus thickness of the layers of the CMOS structure (about $10 \mu \mathrm{m}$ ). Manufacture of such sensor is performing by thinning the base wafer from the back side to required safe thickness what is about $50 \mu \mathrm{m}$ [12].

Within the last fifteen years the team of authors, currently representing the Department of Microelectronics of "LED Technologies of Ukraine" Ltd Company, was participating in the preparation of the current international ALICE experiment at LHC. In particular for the experiment jointly with ALICE collaboration it was developed, designed and manufactured at the level of the best world achievements and in some cases above the microstrip and drift detector modules with using of advanced multi-chip technologies on the basis of flexible adhesive less aluminum-polyimide boards and automated ultrasonic welding processes of ribbon aluminum leads.

Such approach allowed us to maintain the modern level of development and their competitiveness. Currently "LED Technologies of Ukraine" continues to work in the new projects in the field of experimental research in high-energy physics, in particular in the projects on upgrade of the detector modules and components for the detector systems of ALICE, ATLAS and LHCb experiments (CERN, Switzerland), as well as in the new experiments: CBM experiment (GSI, Germany) and Mu3e experiment (Paul Scherrer Institute, Switzerland).
2.4. Features of design-technological solutions of flexible-rigid pixel detector modules for upgraded Inner Tracking System of ALICE experiment

Reducing the material budget and mass of the detector layers in ITS is particularly important for improving the resolution at visualization of the particle collision events on the surface of sensitive elements. In general the reducing of the total material budget can significantly improve the tracking process of investigated particles and their resolution.

At development of high-tech products, what the detector modules are, it is very important to choose the most optimal method of creation of electrical interconnections between the components of the detector modules to meet strict requirements at ensuring high level of long-term reliability $[13,14]$.

Taking into account the requirements and features of design-technological solutions of the flexible-rigid pixel detector modules for upgrade the Inner Tracking System of ALICE experiment two methods for creating the electrical interconnection have been chosen: laser point soldering and ultrasonic welding. This choice is due to the fact that all contact pads on MAPS sensor are arranged on one upper side of the sensor.

\subsection{Laser soldering}

As it is mentioned above as one of the possible method for creating the electrical interconnects in the detector modules the method of laser soldering was chosen. Contract pads on the pixel sensor for connecting by laser soldering are made of aluminum with deposited Ni/Au layers. The laser soldering has industrial application and might be used for connecting the contact joints of monolithic pixel sensors with metal layers of the flexible circuit boards through via (throw-holes) in polyimide layers using the solder balls. The balls are melted locally by laser beam. This allows to reduce thermal overload of the detector modules structures as heat is generated in a small region which is limited by size of the contact pads. However in this case, as shown by practical studies of such technology, during soldering the thin $(50 \mu \mathrm{m})$ semiconductor devices may cause localized overheating of the devices in solder area which might leads to cracks and other damage of the silicon devices. 


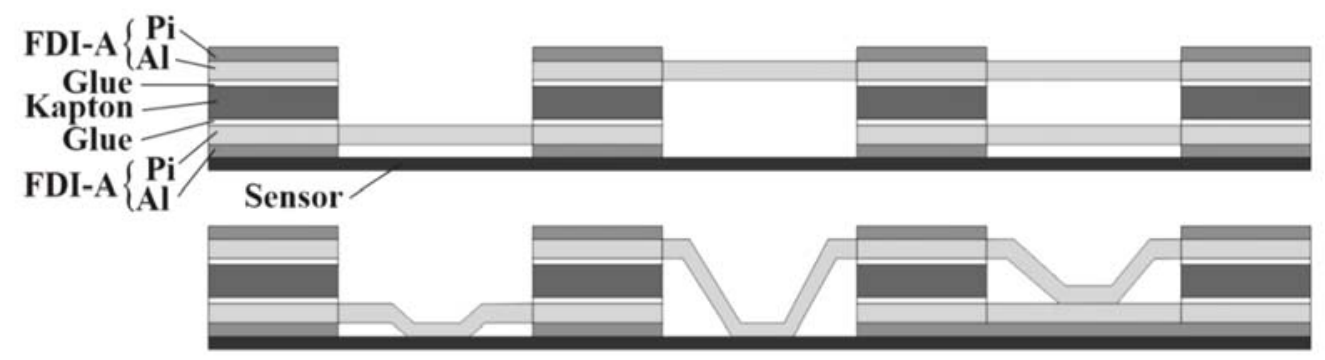

Fig. 2. Types of connections of multilayer board for the semiconductor device and interlayer connection inside the board: bottom layer connection to the device (to the left), top layer connection to the device (in the middle), interlayer connection (to the right).

Obviously that one of the key features of the laser soldering which is required very careful control of the heating process at the solder area. Laser beam spot sizes need to be optimized and matched with the size of the older balls (hundreds micrometers) which under heating should be commensurate to the size of holes in the flexible circuit boards.

The laser soldering requires very high manufacture precision for the tools positioning and placing of the solder microballs.

Thus despite of obvious advantages of the laser soldering it has significant disadvantages for contact connections of the monolithic pixel sensors with metal layers of flexible commutation boards. The main disadvantages of the laser soldering are:

- necessity to use high-precision equipment for the soldering (positioning accuracy of a laser are micrometers);

- necessity to ensure very high flatness of flexible board position with respect to the semiconductor device (sensor) and repeatability of the gap between them (what is awkward at assembly of multisensor modules);

- presence of thermal influence on the semiconductor device that taking into account MAPS thickness about $50 \mu \mathrm{m}$ can carried out to mechanical damage of the device;

- very high required precision for manufacture as the board and the holes for the placing of the solder balls to avoid partial reflow or burning of the sensor;

- absence of possibility for carrying out the visual inspection of solder joints quality;

- very high complexity of qualitative repair of the assemblies.

\subsection{Automated ultrasonic point welding}

An alternative technique without disadvantages related to the laser soldering is automated technology of aluminum ribbon leads of flexible boards to the contact pads of silicon pixel sensors using ultrasonic point welding. Such technology is so-called SpTAB (Single point Tape Automated Bonding) and at its core is aluminum COF-assembly technology. This technology has been successfully applied by the team of authors in creating the microstrip and drift detector modules for existing Inner Tracking System of ALICE experiment [8]. The main features of this approach are using the aluminumpolyimide less adhesive dielectrics and SpTAB techniques for connecting aluminium leads to the contact pads of semiconductor devices (sensors, ASICs). Schematically basic variants of connections realization for multilayered board (top and bottom layers) for the semiconductor device and interlayer connections inside the board are depicted in Fig. 2.

Above described technology has significant advantages and the main ones are:

- ultrasonic welding aluminum leads of flexible boards or aluminum pads of pixel chip ensures uniformity, high reliability and mechanically stable connection;

- absence of heavy metals (Au, Sn) which are present at the soldering;

-it is not needed the tinning contact pads of semiconductor devices what allows to reduce manufacturing costs of such devices;

- using such technology for direct connection between flexible layers of multilayered boards to the pads of pixel chips;

- possibility to use standard industrial automated equipment for the basic assembly processes (welding, gluing and encapsulation).

Table shows the main features of existing laser soldering and ultrasonic welding technologies for the contact joints of monolithic pixel sensors with metal layers of the flexible commutation boards. From analysis of the features of the laser soldering and ultrasonic welding technologies (Table) it can be concluded that the design-technological, physical, technical and reliability parameters of the pixel detector modules manufac- 
Table. Key features of laser soldering and ultrasonic welding technologies

\begin{tabular}{|c|c|}
\hline Laser soldering & Ultrasonic welding (SpTAB) \\
\hline $\begin{array}{l}\text { On pixel chip with Al contact pads with } \mathrm{Ni}-\mathrm{Au} \\
\text { coating it is mounted the flexible board made of } \\
\text { double-sided copper laminated polyimide using } \\
\text { Sn-Ag solder balls } 200 \mu \text { m diameter. Holes for } \\
\text { soldering in the flexible board also have Ni-Au } \\
\text { coating }\end{array}$ & $\begin{array}{l}\text { To Al-contact pads of the pixel chip there are } \\
\text { welding ribbon leads of multilayered flexible } \\
\text { boards made of aluminum-polyimide material, } \\
\text { width leads up to } 100 \mu \mathrm{m}\end{array}$ \\
\hline $\begin{array}{l}\text { Cu thickness is } 18 \mu \mathrm{m}, \mathrm{Ni}-8 \mu \mathrm{m}, \mathrm{Au}- \\
\text { nanometers }\end{array}$ & Al thickness is $30 \mu \mathrm{m}$ \\
\hline $\begin{array}{l}\text { Specific electrical resistance } \mathrm{Sn}-\mathrm{Ag} \text { solder alloy, } \\
\mathrm{Om} \cdot \mathrm{cm} \approx 13.1 \cdot 10^{-6}\end{array}$ & $\begin{array}{l}\text { The electrical resistivity of aluminum } \mathrm{Om} \cdot \mathrm{cm} \approx \\
4.3 \cdot 10^{-6}\end{array}$ \\
\hline Copper radiation length, $\mathrm{cm} X_{0 \mathrm{Cu}} \approx 1.43$ & Radiation length of aluminum, $\mathrm{cm} X_{0 \mathrm{Cu}} \approx 8.9$ \\
\hline Time for creating single solder joint, $\mathrm{s} \approx 12$ & Time for creating single weld joint, $\mathrm{s} \approx 1$ \\
\hline $\begin{array}{l}\text { High temperature influence of laser on solder } \\
\text { points (local heating of solder joint) }\end{array}$ & Absence of thermal influence on the pixel chip \\
\hline $\begin{array}{l}\text { Absence of mechanical influence on the pixel } \\
\text { chip }\end{array}$ & $\begin{array}{l}\text { Presence of mechanical influence on the pixel } \\
\text { chip during welding leads of the board to the } \\
\text { contacts of the chip }\end{array}$ \\
\hline $\begin{array}{l}\text { Absence of possibility for visual inspection at } \\
\text { aligning flexes board to chips during soldering } \\
\text { process }\end{array}$ & $\begin{array}{l}\text { Possibility of visual control for aligning of the } \\
\text { boards to the chip during welding process }\end{array}$ \\
\hline $\begin{array}{l}\text { Complex system for aligning and placing of sol- } \\
\text { der balls and their fixing. Special equipment for } \\
\text { solder joints (which are inaccessible) is required }\end{array}$ & $\begin{array}{l}\text { Welding processes are adapted for using } \\
\text { industrial automated welding equipment such as } \\
\text { Delvotec-6400, Kulicke \& Soffa } 8090 \text { etc. }\end{array}$ \\
\hline $\begin{array}{l}\text { High cost and high labour-output ratio of assem- } \\
\text { bling pixel modules }\end{array}$ & $\begin{array}{l}\text { Relatively low cost and low labour-output ratio } \\
\text { of assembling pixel modules }\end{array}$ \\
\hline $\begin{array}{l}\text { Always there is the danger of loss of solder } \\
\text { joints quality. There is no } 100 \% \text { guarantee on } \\
\text { quality of alloying contacts pads of the sensor } \\
\text { and board }\end{array}$ & $\begin{array}{l}\text { Ability to quick repair weld joints without } \\
\text { reducing contact characteristics during } \\
\text { manufacture process of the pixel module }\end{array}$ \\
\hline $\begin{array}{l}\text { In solder joints there are not ensuring resis- } \\
\text { tance to mechanical and thermal cycling effects } \\
\text { due to mismatch of thermal linear expansion of } \\
\text { used materials }\end{array}$ & $\begin{array}{l}\text { In welded joints ensures high resistance to } \\
\text { mechanical and thermal cycle influences. In } \\
\text { uniform Al-Al weld joint mismatch thermal } \\
\text { linear expansion factor of used materials is } \\
\text { absent }\end{array}$ \\
\hline
\end{tabular}

tured with using the ultrasonic welding processes have several advantages compared to the pixel detector modules made using the laser soldering processes. This particularly applies to radiation length of the detector modules based on flexible multilayered boards made of aluminum foil which is about 6 times higher than the radiation length of copper, their high resistance to mechanical and thermal cycle influences, productivity of the assembly process, as well as the higher conductivity of the weld joints compared to the solder joints with using $\mathrm{Sn}-\mathrm{Ag}$ solder alloys.

For verifying the features and advantages of the detector modules based on MAPS sensors and flexible multilayered boards made of adhesive less aluminiumpolyimide dielectrics a number of designtechnological mock-ups and their research are carried out.

\section{Results and discussion}

Results of studying the mock-ups and prototypes of pixel detector module based on multilayered aluminum-polyimide flexible board.

For verifying the feasibility of realization of innovative detector modules based on the MAPS sensors and flexible aluminum-polyimide multilayered boards the following works were performed:

- development and manufacture of single chips detector module prototype with functional MAPS sensor;

- development and manufacture of detector module full-scale mock-up with 14 MAPS dummy sensors to studying the effect of mechanical influence during ultrasonic welding process on thin semiconductor devices such as MAPS sensors of $50 \mu \mathrm{m}$ thick. 


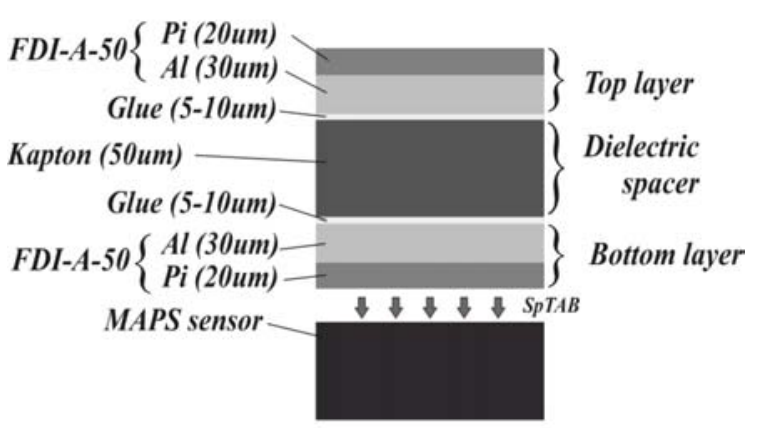

Fig. 3. Structure of multilayered flexible communication board.

For matching to the basic requirement for the multi-layered board-impedance value for signal traces should be $100 \mathrm{Ohm}$ and taking into account the design features of commercially available adhesive less lacquer foiled aluminum-polyimide dielectrics the optimal structure of the multilayered flexible boards was determined, which schematic cross section is depicted in Fig. 3. Mentioned in Fig. 2 structure of the flexible multilayered board was used at development and manufacture of the detector module prototypes.

At the first stage the study of the detector module prototype with single MAPS sensor was carried out. For solving such task the flexible multilayer board was designed and manufactured. Material of the top and bottom layers is adhesive less foiled dielectric FDI-A-50 type (aluminium is $30 \mu \mathrm{m}$ thick, polyimide $-20 \mu \mathrm{m}$ ) and material of dielectric spacer is polyimide film PM-A type $50 \mu \mathrm{m}$ thick (Fig. 3).

Within the next stage the multilayered board was assembled with the MAPS sensor, namely ALPIDE type sensor $50 \mu \mathrm{m}$ thick. Assembled prototype is depicted in Fig. 4 Assembling the multi-layered board is performed by laminating and ultrasonic welding (SpTAB). Over 60 board-to-sensor weld joints were done. The detector module prototype was investigated according to test procedures of the pixel modules for upgrade of the Inner Tracking System for ALICE experiment. Studies were carried out in the ALICE collaboration at CERN. Obtained test results of the detector module prototype were satisfactory and confirming the correctness of the applied approaches, choice of materials and manufacturing technology of the module.

The obtained positive results of the detector module prototype tests allow to conclude possibility on applying the above-described design-technological solution of aluminum multilayered board using the ultrasonic welding for creating of the multisensor detector modules based on thin MAPS pixel sensors.

At the next stage of research the fullscale mock-up of the detector module based on three-layer flexible board with 14 thin MAPS sensors (thickness $50 \mu \mathrm{m}$ ) was designed, manufactured and tested. Objective of this stage was checking absence of mechanical damage in the thin silicon sensors at selected regimes of connection of multilayer board to them by the ultrasonic welding method.

Within the research the flexible multilayer board was designed and produced with using of its full-scale mock-up of the module (Fig. 5) was assembled using the MAPS dummy sensors. Over 800 board-to-sensor weld joints were done.

After assembly of the full-scale pixel detector module prototype visual inspection was carried out on to check an absence of mechanical damage of the sensor (cracks, scratches etc.). During inspection there were observed the absence of any visible mechanical damage of the sensors what allows to make a conclusion about possibility of creating the high-quality electrical connection of board-to-sensor by the ultrasonic

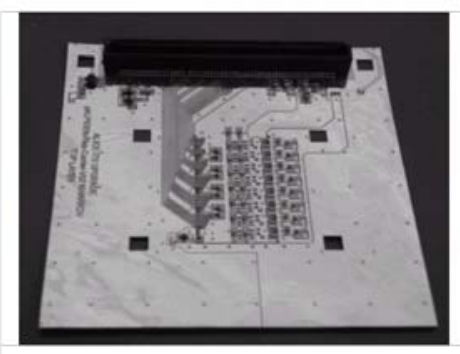

a

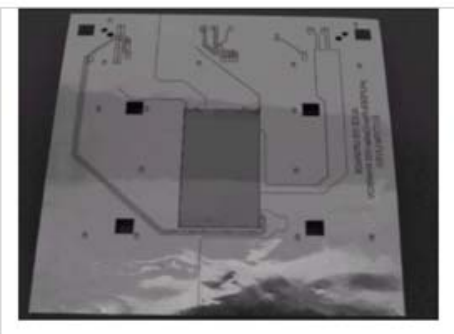

b

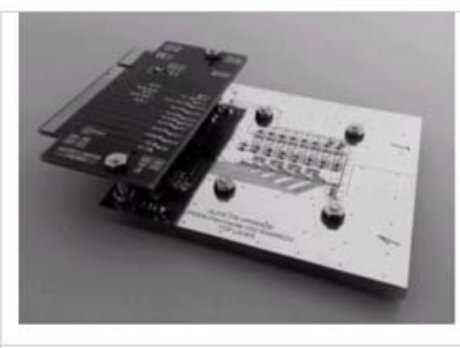

Fig. 4. Assembled prototype of detector module with single MAPS sensor: a - view from the side of the board; $\mathrm{b}$ - side view from side of the sensor; $\mathrm{c}$ - functional module prototype prepared for 


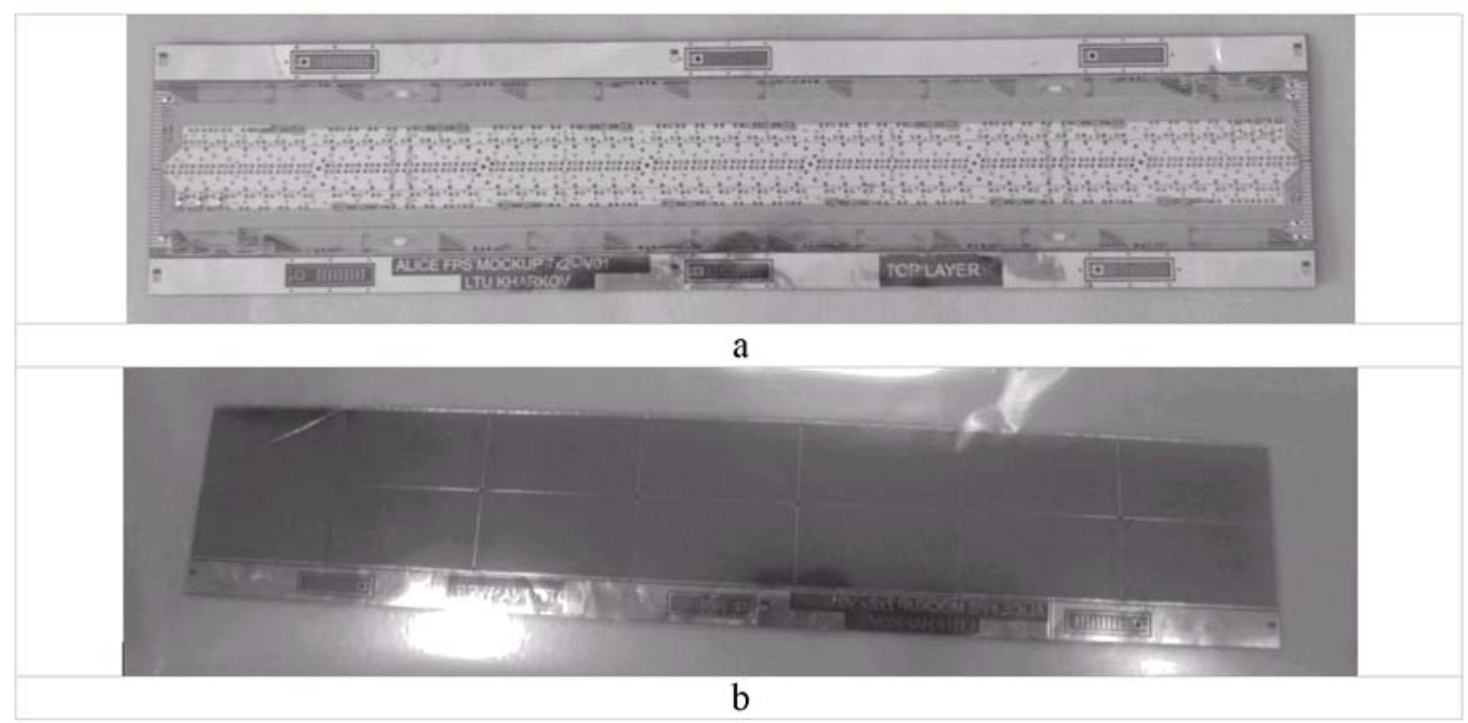

Fig. 5. Assembled full-scale module mock-up with 14 MAPS sensors: a - view from the flexible multilayer board; b - view from the MAPS sensors.

welding as more reliable alternative to creation of the electrical connections of thin silicon sensors with flexible boards by the laser soldering using the solder balls.

Thus, the obtained results of investigations of the prototype and mock-up of the detector modules based on thin MAPS sensors $50 \mu \mathrm{m}$ thick and multilayered flexible boards with layers made of adhesive less aluminum-polyimide dielectrics confirmed the principle possibility of realization of the proposed technical solution for creating the innovative pixel detector modules. The proposed approaches to the development and production of the multi-layered flexible boards and the assembly of pixel sensors based on the ultrasonic welding processes allow to realize in full volume all requirements for the upgrade of the pixel detector modules for Inner Tracking System in the new ALICE experiment.

\section{Conclusions}

Onrush of the technique and technologies level, especially microelectronics, as well as increasing the requirements for detector systems in international experiments in elementary particle physics is a very significant impulse for development of the new innovative design-technological solutions of the detector systems and their components, taking into account that detector modules are one of the major elements. One of the achievements in this direction within the recent years is development of the novel supermodern thin $(50 \mu \mathrm{m})$ monolithic active pixel sensors (MAPS), which include both the sensor element and readout electronics. At the same time for full accordance to the requirements on minimization of material budget in the detecting volume it is indispensable to ensure a reliable electrical commutation of the module components with minimal value of the material budget. Such commutation can be realized using multilayered flexible circuit boards based on aluminum-polyimide less adhesive lacquer foiled dielectrics and COF-assembly technology.

Within performing the given work there were developed and studied prototype and mock-up of the detector module based on thin MAPS sensor ALPIDE type and multilayered boards made of adhesive less lacquer foiled dielectrics with an aluminum conductive layer. Obtained study results for the detector module prototype and mock-up based on the modern MAPS sensors of $50 \mu \mathrm{m}$ thick and aluminum-polyimide multilayered flexible boards using aluminum COF assembly technologies allow to conclude as for the feasibility of the proposed solutions for creating the upgraded Inner Tracking System of international ALICE experiment at LHC in CERN.

The technical result obtained within this work allow to ensure the achievement of tasks for upgrade of the ALICE experiment, the main ones are increasing in almost 6 times the radiation length and reducing pixel size by more than 20 times (and thus increasing the number of pixels per unit of area of the sensor). At once density of pixels is increased by 50 times. High performance of the novel and modern CMOS MAPS 
sensors allow to ensure with their help the maximal achieved currently spatial resolution of the sensors at range less than $30 \mu \mathrm{m}$.

Using CMOS MAPS sensors in the new detector modules allows also reduces of the material budget of single detector layer in ITS in seven times compared to already used design of pixel ladders currently used in the ALICE experiment (chips are $50 \mu \mathrm{m}$ thickness instead of $350 \mu \mathrm{m})$.

Moreover the obtained results, in turn, might have further development in direction of using the given design-structural approaches at creating the innovative detector modules for international physics experiments such as CBM, ATLAS, Mu3e etc.

\section{References}

1. A.P.Tsitovich, Nuclear Electronics, Energoatomizdat, Moscow (1984) [in Russian].

2. A.G.Chilingarov, Coordinate Semiconductor Detectors in Particle Physics, Preprint, SB AS USSR, Institute of Nuclear Physics, Novosibirsk (1990), p.65 [in Russian].

3. M.L.Wolin, Parasitic Processes in Electronic Equipment, Radio and Communications, Moscow (1981) [in Russian].

4. A.D.Knyazev, L.N.Kegichev, B.V.Petrov, Construction of Electronic and Computer Equipment with Regard to Electromagnetic Compatibility, Radio and Communications, Moscow (1982) [in Russian].
5. A.M.Medvedev, Assembly and Mounting of Electronic Devices, Technosphere, Moscow (2007) [in Russian].

6. M.P.Romanov, Assembly and Mounting of Integrated Circuits: Tutorial, UlSTU, Ulyanovsk (2008) [in Russian].

7. V.L.Lanin, A.P.Dostanko, E.V.Teles, Formation of the Conductive Contact Connections in Electronics Products, Publ. Center BSU, Minsk (2007) [in Russian].

8. Technical Design Report of the Inner Tracking System (ITS) CERN/LHCC 99-12 ALICE TDR 4, 18 June 1999, p.360.

9. A.Medvedev, G.Milov, P.Semenov, A.Sergeantov, Construction of Flexible and Flex-rigid PCB, Components and Technologies, 2008, No.6 [in Russian].

10. J.R.Lutz, L.Arnold, I.Baudot et al., TAB bonded SSD module for the STAR and ALICE trackers, in: Proc. of the fifth Workshop on Electronics for LHCE Experiments, Crakow, Poland, 11-15 September (2000), p.152.

11. N.V.Zamirets, V.N.Borschov, A.M.Listratenko et al., Techn. Eng., 2, 3 (2007).

12. Technical Design Report for the Upgrade of the ALICE Inner Tracking System (ITS) CERN-LHCC-2013-024/ALICE-TDR-017, 29 November 2013, p.189.

13. V.N.Borshchov, V.A.Antonova, A.M.Listratenko et al., Techn.Eng., 2, 3 (2009).

14. A.P.Dostanko, M.I.Pikul, A.A.Khmyl, Technology of Manufacture of Computers, Higher School, Moscow (2004) [in Russian]. 